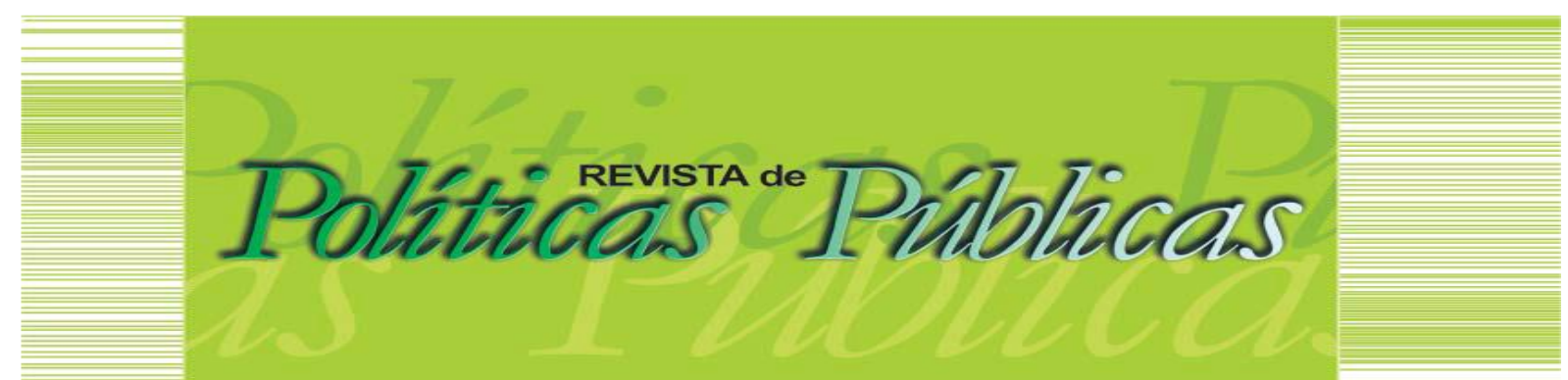

\title{
IMPACTOS DA COVID-19 NO SETOR CULTURAL PORTUGUÊS: como é que os 308 municípios reagiram à pandemia?
}

Manuel Gama1

\begin{abstract}
Resumo
O POLOBS encontra-se a desenvolver uma pesquisa que visa identificar e analisar alguns dos impactos da COVID-19 no setor cultural português. 0 projeto, que conjuga uma abordagem qualitativa com uma abordagem quantitativa, e integra instrumentos e técnicas diversificadas, iniciou-se a 16 de março de 2020 e vai decorrer até 31 de março de 2021. No presente artigo vamos lançar um olhar sobre seis meses de notícias nos 308 municípios portugueses. A análise efetuada permite-nos afirmar,ainda que provisoriamente, queo fluxo de notícias nos websites dos municípios está em linha com 0 pouco peso estratégico que a cultura tem em muitas das dinâmicas das políticas municipais, tendo sido possível identificar um número residual de medidas das autarquias locais para a mitigação, a curto e médio prazos, dos impactos negativos nas organizações e profissionais do setor cultural.
\end{abstract}

Palavras-chave: COVID-19. Cultura. Impactos. Municípios portugueses.

\section{IMPACTS OF COVID-19 ON THE PORTUGUESE CULTURAL SECTOR: how did the 308 municipalities react to the pandemic?}

\section{Abstract}

POLOBS is conducting a research that focuses on the identification and examination of some of the impacts of COVID-19 on the Portuguese cultural sector. Beginning on the 16th of March 2020 and ending on the 31st of March 2021, this project combines qualitative and quantitative approaches and accommodates different tools and techniques. In this article we are going to take a look at six months of news in the 308 Portuguese municipalities. The analysis carried out allows us to affirm, even provisionally, that the flow of news on the websites of the municipalities is in line with the little strategic weight that culture has in many of the dynamics of municipal policies, and it was possible to identify a residual number of measures of the local authorities to mitigate, in the short and medium term, the negative impacts on organizations and professionals in the cultural sector.

Keywords: COVID-19. Culture. Impacts. Portuguese municipalities

Artigo recebido em: 21/12/2020 Aprovado em: 27/05/2021 DOI: http://dx.doi.org/10.18764/2178-2865.v25n1p150-166

\footnotetext{
1 Doutor em Estudos Culturais/Sociologia da Cultura pela Universidade do Minho em Portugal. Pesquisador coordenador no Observatório de Políticas de Ciência, Comunicação e Cultura do Centro de Estudos de Comunicação e Sociedade da Universidade do Minho (PolObs, CECS-UM).Email: manuelgama@ics.uminho.pt
} 


\section{NOTA DE ABERTURA}

Em dezembro de 2020, quando concluímos a presente análise parcial e preliminar dos resultados da pesquisa Impactos da COVID-19 no setor cultural português ${ }^{1}$, estávamos ainda muito longe de perceber verdadeiramente a real amplitude dos múltiplos e diversificados impactos da pandemia de COVID-19, provocada pelo novo coronavírus SARS-COV-2, que foi decretada pela Organização Mundial de Saúde (2020a) nove meses antes. Se, por um lado, é inegável que oritmo acelerado com que vivemos na contemporaneidade podee deve ser encarado como um dos contributos negativos para a rapidez com que a doença se alastrou um pouco por todo o mundo - nomeadamente devido aos modos de vida e hábitos e facilidades de mobilidade entre territórios -, por outro lado, é incontestável que o mesmo ritmo também pode e deve ser encarado como um contributo muitíssimo positivo para a resolução do problema - nomeadamente no campo da saúde pública. A este respeito destaca-se, por exemplo, a aprovação menos de um ano depois de ter sido partilhada pela China da sequência genética do SARS-COV-2 (OMS, 2020b), da primeira vacina contra a COVID-19 pela Medicines and Health Care Products Regulatory Agency (2020).

No setor cultural, os tempos de contaminação e de reação pela pandemia também foram muito curtos. Em Portugal, por exemplo, a contaminação pode ser ilustrada como Despacho n. ${ }^{0} 2836$ $\mathrm{A} / 2020$, de 2 de março, que obrigou os empregadores públicos, nomeadamente os da cultura como a Cinemateca Portuguesa (2020), a elaborarem um plano de contingência alinhado com as orientações emanadas pela Direção-Geral da Saúde (DGS); e a reação do setor cultural privado é mencionada explicitamente na notícia de 12 de março, no qual se refere que "em dias de coronavírus, o teatro chega às plateias através da Internet" (PINTO, 2020).

Foi com este pano de fundo queo Observatório de Políticas de Ciência, Comunicação e Cultura do Centro de Estudos de Comunicação e Sociedade da Universidade do Minho (POLObs),considero relevante, pertinente e urgente a constituição de uma equipa multidisciplinar com o objetivo macro de monitorizar os impactos da COVID-19 no setor cultural português. Tendo sido definidasquatro dimensões de análise, correspondentes a quatroobjetivos específicos que passamos a convocar sumariamente:

1) aferir o impacto mediático das consequências da COVID-19 no setor cultural português;

2) identificar o fluxo de notícias produzidas pelos 308 municípios e pelas 25 entidades intermunicipais (EIM's) que abordam sincronicamente aspetos relacionados com COVID-19 e cultura; 
3) analisar as iniciativas do Governo, através do Ministério da Cultura e de organismos/entidades tutelados pelo Ministério da Cultura, para enfrentar os constrangimentos provocados pela COVID-19;

4) avaliar os impactos, esperados e observados, que a COVID-19 teve e terá nas organizações e profissionais do setor cultural português.

Conjugando uma abordagem qualitativa com uma abordagem quantitativa, inspirado nos contributos teóricos e metodológicos de autores como Bardin (2007), Bell (2008), Chaumier (1979),Creswell(2008), Fernandes (2010), Matos (2014), Quivy \& Campenhoudt (2005) e Sampieri, Collado \& Lúcio (2006), o projeto de pesquisa, desenvolvido entre março de 2020 e março de 2021, integra a utilização de instrumentos e técnicas diversificados, tais como:

a) análise documental (e.g. legislação, notícias na imprensa, websites);

b) inquérito por questionário a organizações e profissionais do setor cultural português;

c) depoimentos de profissionais do setor cultural português.

No que se refere à disseminação dos resultados do projeto, considerou-se fundamental disponibilizar regularmente a análise, ainda que preliminar, dos dados que vão sendo recolhidos, pois só assim poderão ser relevantes na procura de soluções para os impactos que a COVID-19 terá no tecido cultural português.

É nesse contexto que surge o presente artigo, apresentando uma análise consolidada de dados recolhidos na segunda dimensão do estudo ao longo do primeiro semestre da pandemia. Sobre a pertinência de analisar os Impactos da COVID-19 no setor cultural português através das atividades dos municípios, relembramos que em Portugal a "crescente visibilidade do cultural, não chegou a responder a uma política cultural que, de modo articulado e sistemático, acompanhasse e estimulasse as mudanças emergentes na sociedade civil" (SANTOS, 1998, p.411); e que "acentralidade da cultura nos discursos políticos locais não corresponde necessariamente a concretizações" (CASQUEIRA, 2007, p.493).

\section{OS MUNICÍPIOS E AS ENTIDADES INTERMUNICIPAIS PORTUGUESAS}

Em Portugal, a administração pública à escala municipal está, genericamente, enquadrada pela Lei . $^{0}$ 75/2013, que "Estabelece o regime jurídico das autarquias locais, aprova 0 estatuto das entidades intermunicipais, estabelece o regime jurídico da transferência de competências do Estado para as autarquias locais e para as entidades intermunicipais e aprova o regime jurídico do associativismo autárquico" (DIÁRIO DA REPÚBLICA, 2013, p.5688), tendo sido, por isso, no presente 
estudo, utilizada a Nomenclatura das Unidades Territoriais para Fins Estatísticos (NUT) que agrupam os 308 municípios de Portugal em 25 NUTS 3, que correspondem a outras tantas EIM's, sete NUTS 2, que agrupam as NUT 3, e três NUTS 1, que agrupam as sete NUT 2.

Para identificar o fluxo de notícias produzidas pelos municípios e pelas EIM's que abordavam sincronicamente aspetos relacionados com COVID-19 e cultura, fez-se uma pesquisa num total de 333 websites (308 municípios e 25 EMl's), sendo que, de cada website, só foram retiradas informações provenientes das secções de notícias, ou similares, a partir de três palavras-chave covid-19, coronavírus e cultura - definidas para o efeito. Realça-se que para a operacionalização da dimensão cultural se optou por utilizar os 10 domínios da cultura definidos em 2016 no âmbito da Conta Satélite da Cultura 2010-2012 (INSTITUTO NACIONAL DE ESTATÍSTICA I.P., 2016).

Em termos metodológicos, definimos que de cada notícia seriam registados um conjunto de dados que nos permitissem efetuar, numa primeira fase, uma análise de natureza quantitativa, regressando posteriormente à base de dados para efetuar uma análise de natureza qualitativa, tendo em consideração um conjunto de categorias definidas para o efeito. Assim, na base de dados criada registaram-se as seguintes informações de cada item: designação do município ou EIM de onde a notícia foi extraída; título da notícia; hiperligação de acesso; data de publicação.Sublinha-seque na pesquisa também se procurou identificar, independentemente de estar diretamente relacionada com a cultura, a primeira notícia publicada no mês de março relacionada com a COVID-19, pois assim será possível perceber de forma mais nítida a distância temporal com as notícias sobre COVID-19 e cultura, que podem ser um reflexo visível junto da população em geral de quando é que os respetivos municípios e entidades começaram a colocar a cultura no seu leque de preocupações com 0 surgimento da pandemia.

Antes de avançarmos para a convocação sintética da análise em curso, sublinha-se que, tendo em consideração o peso residual das notícias identificadas nos 25 websites das EIM's, se optou por, nesta fase, não integrar as notícias destes websites na análise que se segue. Assim sendo, no presente artigo propomos uma breve viagem pelas 3.955 notícias publicadas, entre 1 de março e 31 de agosto de 2020, nos 308 websites dos municípios portugueses e que nos vão permitir apresentar algumas conclusões preliminares sobre os impactos da COVID-19 nas dinâmicas culturais municipais.

\section{UM OLHAR QUANTITATIVO PARA OS WEBSITES DOS MUNICÍPIOS}

Para a análise dos itens identificados foram criados subgrupos em função da dimensão territorial - 29 subgrupos (22 ao nível das NUTS 3; três dos territórios em que as NUTS 2 integram uma única NUT 3; e quatro ao nível das NUTS 2 com os territórios que integram diversas NUTS 3) - e da 
dimensão temporal, com a fragmentação da amostra em blocos de notícias quinzenais, mensais e trimestrais.

Gráfico 1 - Distribuição das notícias e dos municípios pelas NUTS 2

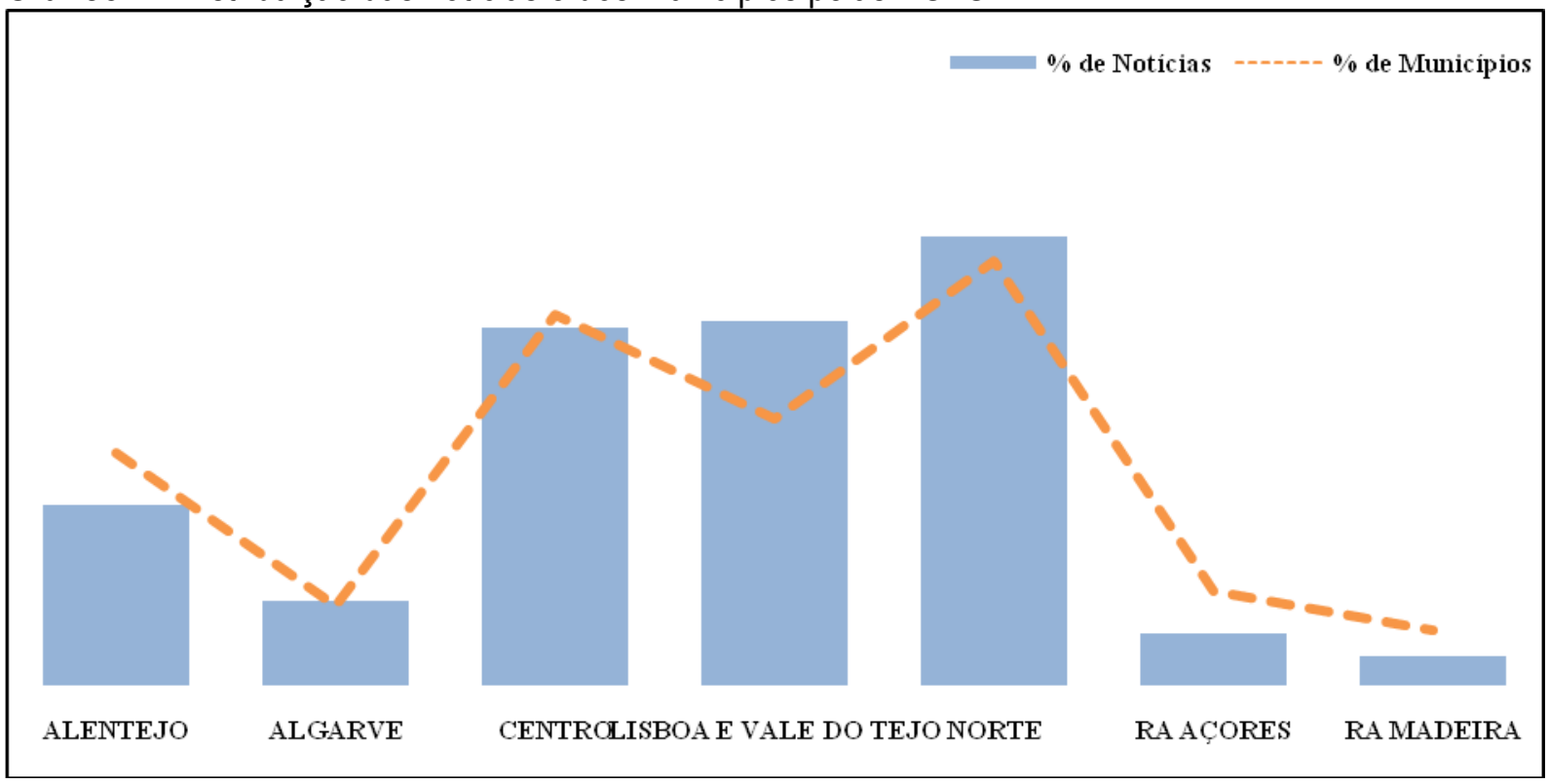

Fonte: Elaboração própria

Um primeiro olhar meramente quantitativo sobre os itens identificados revelou, como se pode observar no Gráfico 1, que o peso que cada NUT 2 tem no território nacional, ou seja o número de municípios que agrega, nem sempre teve correspondência no contributo que os municípios dos diferentes territórios deram para o conjunto de notícias identificadas. O facto de, por exemplo, a Região Autónoma do Açores (RA Açores) representar 6,2\% dos municípios portugueses e só ter sido responsável por $3,4 \%$ das notícias identificadas, pode ser um sinal, ainda que ténue, sobre o peso que a cultura tem nas prioridades de políticas públicas municipais daquele território. Sendo inegável que, para se poder confirmar e afirmar que existe uma relação entre o peso mediático e o peso político da cultura, é necessário entrar em linha de conta com outras dimensões de análise, a verdade é que não deixa de ser um dado importante a ter em conta. Também estamos conscientes de que se entrarmos em linha de conta com a percentagem de população residente em cada território, se observam alterações nas relações dos resultados obtidos. Sob este ponto de vista e no caso específico da RA Açores, o peso relativo das notícias publicadas ultrapassa em $0,9 \%$ o peso que a sua população residente tem na população residente em Portugal no ano de 2019, contudo não se considerou relevante incluir esta dimensão de análise na pesquisa, para não concorrer para a ideia de que a implementação de políticas públicas culturais está diretamente relacionada com a dimensão e o número de residentes em determinado território, o que colocaria os municípios pouco povoados numa situação ainda mais frágil. 
O Gráfico 2, que sintetiza as médias globais de notícias publicadas nos 308 websites (por EIM e a nível nacional) sobre a temática de cultura e COVID-19, parece reforçar a ideia de que houve abordagens muito distintas por parte dos municípios para dar resposta ao inesperado da situação e aos constrangimentos da pandemia no setor cultural. Se a média nacional de publicação de uma notícia quinzenal já não é, per si, sinónimo de prioridade municipal de, pelo menos e, por exemplo, prestar informações atualizadas às organizações e profissionais do setor cultural dos territórios dos constrangimentos emanados por orientações do Governo ou à população em geral sobre as necessárias adaptações à oferta cultural local, o que dizer sobre municípios, como os da EIM Alto Alentejo, em que a média é de menos de uma notícia a cada seis semanas. Sobre a média nacional, acresce ainda que tal só foi conseguido devido aos contributos dos grandes centros populacionais da Área Metropolitana de Lisboa e da Área Metropolitana do Porto.

Gráfico 2 - Médias de notícias publicadas por município em cada NUT 3 e a nível nacional

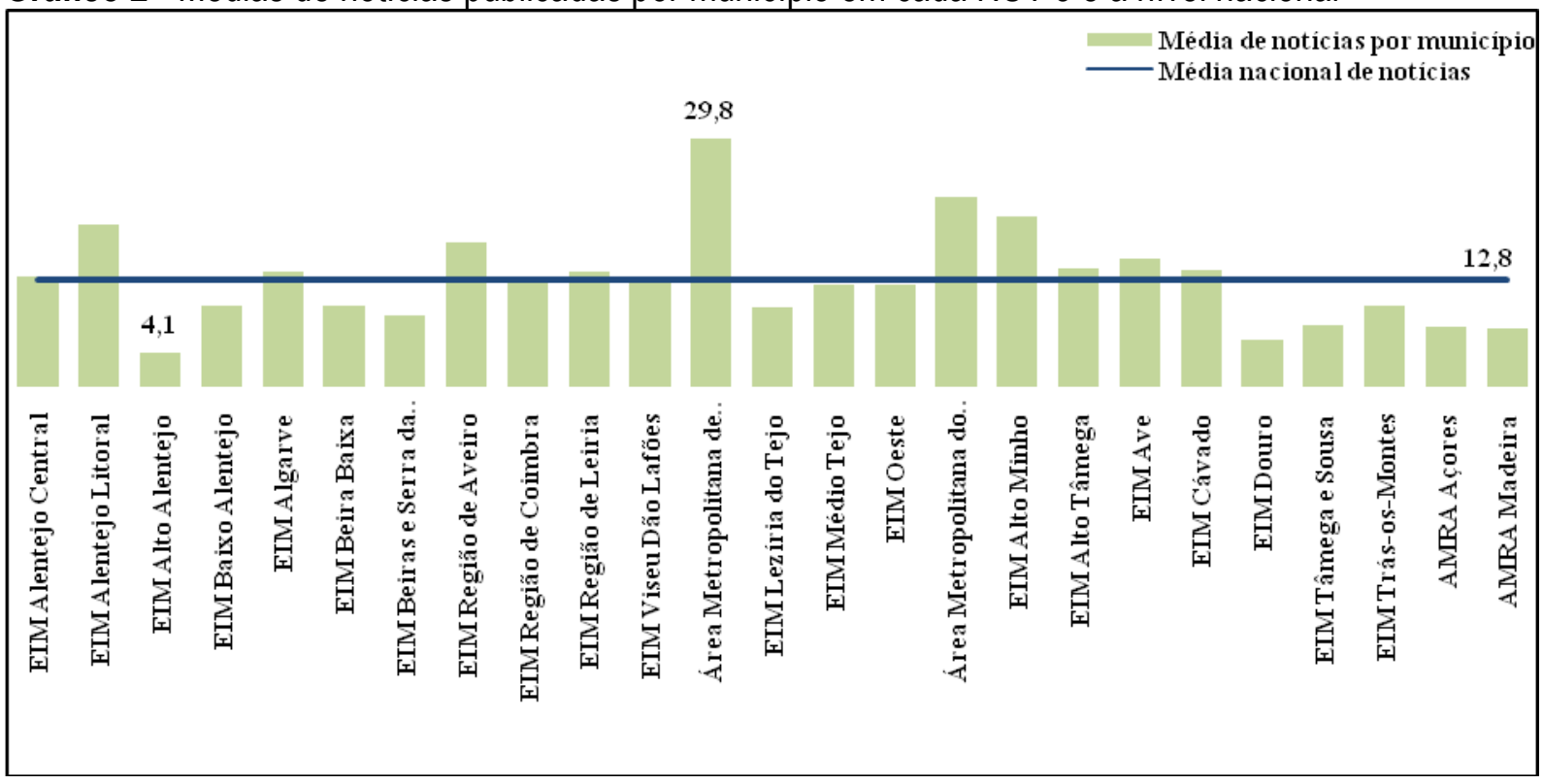

Fonte: Elaboração própria

No que concerne à dimensão temporal, o Gráfico 3 permite perceber rapidamente que, depois do primeiro conjunto de notícias publicadas na primeira quinzena de março (que representam $16,5 \%$ do total das notícias publicadas nos seis meses em análise), os municípios portugueses começaram a reduzir paulatinamente o fluxo de notícias sobre a dimensão cultural da COVID-19, o que também pode ser um indicador particularmente importante sobre a presença da cultura na escala de prioridades das políticas públicas municipais para mitigar os efeitos da COVID-19. 
Gráfico 3 - Distribuição quinzenal das 3.955 notícias publicadas nos 308 websites

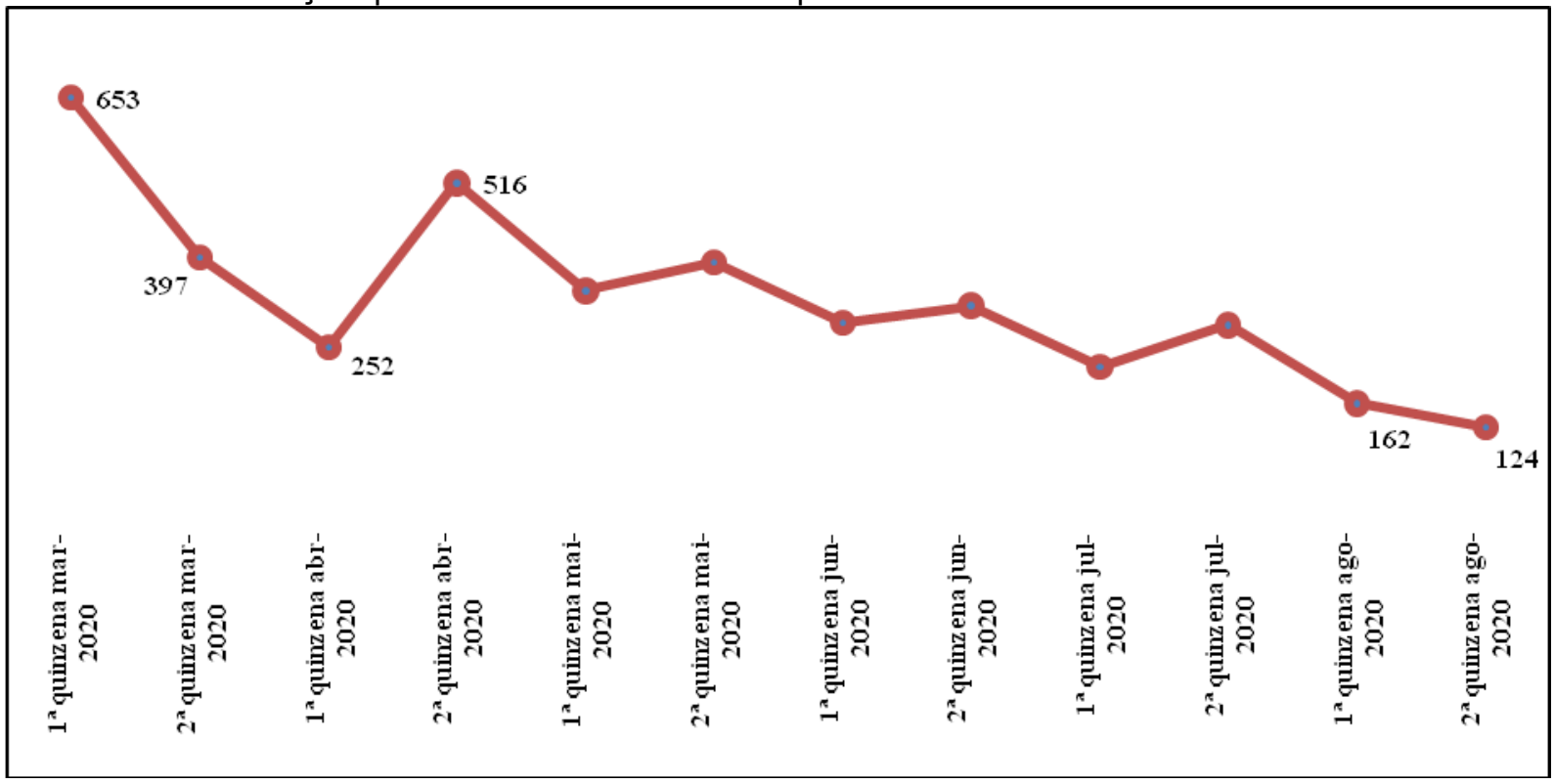

Fonte: Elaboração própria

Depois de efetuada a análise quantitativa a partir das dimensões territorial e temporal, que convocamos brevemente e de forma meramente ilustrativa do trabalho que está em curso, segue-se um olhar qualitativo para os títulos das notícias para identificar as grandes temáticas abordadas ao longo do período em análise.

\section{UM OLHAR QUALITATIVO PARA OS WEBSITES DOS MUNICÍPIOS}

Os 3.955 itens identificados foram categorizados por temática, sendo que para além da subcategoria primeira publicação COVID-19 março e da subcategoria outras temáticas, se estipularam mais 10 subcategorias, a saber: recomendações da DGS; plano de contingência municipal; medidas extraordinárias e temporárias; estado de emergência nacional; adiamento de atividades culturais; cancelamento de atividades culturais; adaptação de atividades culturais; encerramento de espaços e serviços; utilização de recursos culturais (e.g. infraestruturas, financeiros) a favor da COVID-19; e linhas de apoio para a cultura. Realça-se que na análise temática, cada item poderia ser enquadrado em várias das subcategorias definidas e que, na subcategoria outras temáticas, foram incluídos os itens com temáticas não previstas nas subcategorias anteriores, mas também itens em que a dimensão cultural não era exclusiva ou o foco principal das notícias identificadas.

O Gráfico 4 permite perceber a preponderância de medidas que visaram, essencialmente, a adaptação e o cancelamento de atividades culturais, que no fundo não foram mais do que respostas muito imediatas a orientações emanadas pelo Governo, como o Decreto n. ${ }^{0}$ 2-A/2020 (DIÁRIO DA 
REPÚBLICA, 2020a), de 20 de março, que procedeu à execução da declaração do estado de emergência, determinando, nomeadamente, o encerramento de instalações e estabelecimentos destinados a atividades culturais e artísticas, que na realidade já tinha começado a acontecer de forma generalizada um pouco por todo o território nacional com o Decreto-Lei n. ${ }^{0}$ 10-A/2020 (DIÁRIO DA REPÚBLICA, 2020b), de 13 de março, que, entre outros, limitou o acesso a espaços frequentados pelo público.

Gráfico 4 - Categorização das 3.955 notícias publicadas nos 308 websites

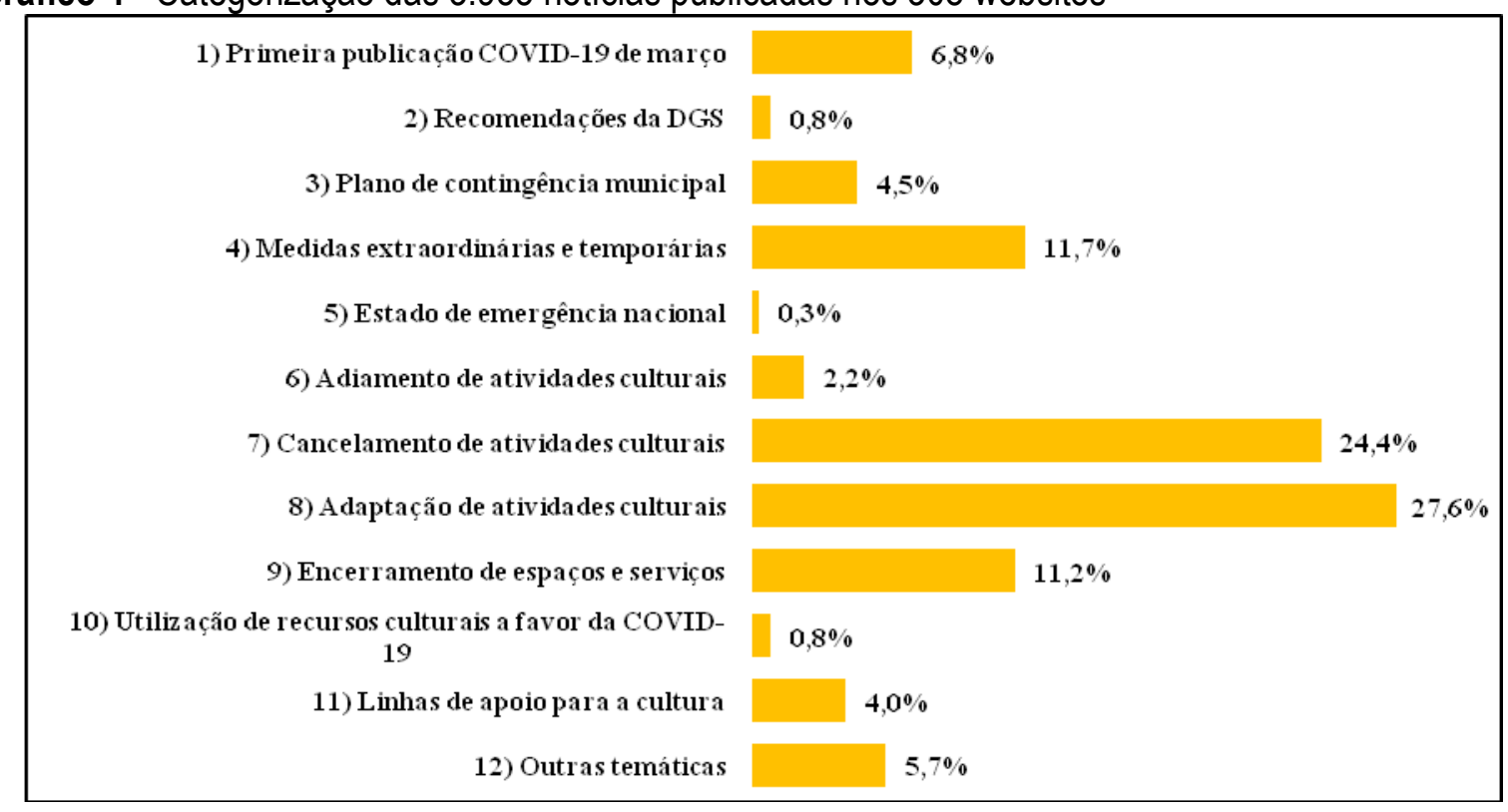

Fonte: Elaboração própria

Na Tabela 1 sintetizamos os dados provenientes do cruzamento da dimensão territorial com a dimensão temática:sendo de destacar que em cada uma das 12 subcategorias definidas se pode consultar, nas linhas superiores, os dados referentes à percentagem relativa em função das sete NUTS 2 e, nas linhas inferiores, os dados referentes à percentagem em função da NUT 2 a que a coluna diz respeito, aparecendo salientados os valores máximos e mínimos.

Tabela 1 - Categorização das notícias por NUT 2

\begin{tabular}{|r|c|c|c|c|c|c|c|}
\cline { 2 - 8 } \multicolumn{1}{c|}{} & ALENTEJO & ALGARVE & CENTRO & $\begin{array}{c}\text { LISBOAE } \\
\text { VALE DO } \\
\text { TEJO }\end{array}$ & NORTE & RA AÇORES & RA MADEIRA \\
\hline 1) Primeira publicação COVID-19 & $15,2 \%$ & $5,2 \%$ & $24,6 \%$ & $17,2 \%$ & $28,2 \%$ & $6,1 \%$ & $3,6 \%$ \\
\cline { 2 - 8 } de março & $9,0 \%$ & $6,0 \%$ & $7,1 \%$ & $5,2 \%$ & $6,6 \%$ & $10,9 \%$ & $11,2 \%$ \\
\hline \multirow{2}{*}{ 2) Recomendações da DGS } & $11,8 \%$ & $0 \%$ & $44,1 \%$ & $5,9 \%$ & $35,3 \%$ & $0 \%$ & $2,9 \%$ \\
\cline { 2 - 9 } & $0,8 \%$ & $0 \%$ & $1,4 \%$ & $0,2 \%$ & $0,9 \%$ & $0 \%$ & $1,0 \%$ \\
\hline 3) Plano de contingência & $12,3 \%$ & $4,9 \%$ & $22,5 \%$ & $19,6 \%$ & $28,4 \%$ & $6,9 \%$ & $5,4 \%$ \\
\cline { 2 - 9 } municipal & $4,8 \%$ & $3,8 \%$ & $4,3 \%$ & $3,9 \%$ & $4,4 \%$ & $8,0 \%$ & $11,2 \%$ \\
\hline 4) Medidas extraordinárias e & $16,4 \%$ & $5,7 \%$ & $24,4 \%$ & $23,3 \%$ & $24,2 \%$ & $3,8 \%$ & $2,3 \%$ \\
\cline { 2 - 8 } & $16,7 \%$ & $11,3 \%$ & $12,1 \%$ & $12,1 \%$ & $9,7 \%$ & $11,5 \%$ & $12,2 \%$ \\
\hline 5 temporárias Estado de emergência nacional & $28,6 \%$ & $7,1 \%$ & $7,1 \%$ & $42,9 \%$ & $7,1 \%$ & $0 \%$ & $7,1 \%$ \\
\hline
\end{tabular}


IMPACTOS DA COVID-19 NO SETOR CULTURAL PORTUGUÊS: como é que os 308 municípios reagiram à pandemia?

\begin{tabular}{|r|c|c|c|c|c|c|c|}
\hline & $0,8 \%$ & $0,4 \%$ & $0,1 \%$ & $0,6 \%$ & $0,1 \%$ & $0 \%$ & $1,0 \%$ \\
\hline 6) Adiamento de atividades & $14,1 \%$ & $5,1 \%$ & $18,2 \%$ & $31,3 \%$ & $30,3 \%$ & $1,0 \%$ & $0 \%$ \\
\cline { 2 - 8 } culturais & $2.7 \%$ & $1,9 \%$ & $1,7 \%$ & $3,0 \%$ & $2,3 \%$ & $0,6 \%$ & $0 \%$ \\
\hline culturais Cancelamento de atividades & $9,6 \%$ & $4,8 \%$ & $23,6 \%$ & $20,7 \%$ & $36,3 \%$ & $3,4 \%$ & $1,5 \%$ \\
\cline { 2 - 8 } & $20,3 \%$ & $19,9 \%$ & $24,3 \%$ & $22,5 \%$ & $30,4 \%$ & $21,8 \%$ & $17,3 \%$ \\
\hline 8) Adaptação de atividades & $9,4 \%$ & $6,3 \%$ & $24,3 \%$ & $28,5 \%$ & $26,9 \%$ & $2,6 \%$ & $2,0 \%$ \\
\cline { 2 - 8 } culturais & $22,6 \%$ & $29,7 \%$ & $28,4 \%$ & $34,9 \%$ & $25,5 \%$ & $18,4 \%$ & $25,5 \%$ \\
\hline 9) Encerramento de espaços e & $10,0 \%$ & $5,7 \%$ & $24,8 \%$ & $23,0 \%$ & $31,4 \%$ & $3,1 \%$ & $2,0 \%$ \\
\cline { 2 - 8 } serviços & $9,8 \%$ & $10,9 \%$ & $11,8 \%$ & $11,5 \%$ & $12,1 \%$ & $9,2 \%$ & $10,2 \%$ \\
\hline 10) Utilização de recursos & $5,6 \%$ & $0 \%$ & $22,2 \%$ & $22,2 \%$ & $47,2 \%$ & $2,8 \%$ & $0 \%$ \\
\cline { 2 - 8 } culturais a favor da coviD-19 $\%$ & $0,4 \%$ & $0 \%$ & $0,7 \%$ & $0,8 \%$ & $1,3 \%$ & $0,6 \%$ & $0 \%$ \\
\hline \multirow{2}{*}{ 11) Linhas de apoio para a cultura } & $3,9 \%$ & $6,7 \%$ & $23,2 \%$ & $32,8 \%$ & $26,1 \%$ & $5,6 \%$ & $1,7 \%$ \\
\cline { 2 - 8 } & $1,3 \%$ & $4,5 \%$ & $3,9 \%$ & $5,8 \%$ & $3,6 \%$ & $5,7 \%$ & $3,1 \%$ \\
\hline \multirow{2}{*}{ 12) Outras temáticas } & $21,6 \%$ & $12,0 \%$ & $17,4 \%$ & $25,5 \%$ & $15,4 \%$ & $8,9 \%$ & $2,7 \%$ \\
\cline { 2 - 8 } & $10,7 \%$ & $11,7 \%$ & $4,2 \%$ & $6,5 \%$ & $3,0 \%$ & $13,2 \%$ & $7,1 \%$ \\
\hline
\end{tabular}

Fonte: Elaboração própria

Seguem algumas breves considerações a partir de um primeiro olhar para a Tabela 1:

- da análise das três subcategorias diretamente relacionadas com as atividades culturais $(6,7,8)$, que nos permite perceber como é que a oferta cultural municipal foi afetada, torna-se nítido que a adaptação e o cancelamento de atividades foram as opções mais utilizadas pelos municípios, representando, respetivamente, $27,6 \%$ e $24,4 \%$ do total dos itens identificados - destacando-se Lisboa e Vale do Tejo como a NUT que mais eco deu à adaptação de atividades, nomeadamente o Município de Cascais com a transmissão online de peças de teatro e o Município de Palmela (2020) com o projeto "Da minha casa vejo o mundo", e o Norte como a NUT a registar o maior número de cancelamentos de atividades, nomeadamente o Município de Matosinhos (2020) com o anúncio de que "As Festas do Senhor de Matosinhos foram canceladas" e o Município do Porto (2020) com a tomada de decisão de que "Fórum do Futuro não se realizará em 2020";

- a subcategoria 10) foi a segunda em que menos foi possível enquadrar os itens identificados, mas a verdade é que foi identificada em cinco NUTS 2, representando um máximo de $1,3 \%$ das notícias do Norte, contudo considerou-se que esta poderia ser uma dimensão de análise particularmente relevante para verificar se os recursos normalmente afetos à cultura (e.g. financeiros, humanos, infraestruturais) iriam ser canalizados para fazer face à COVID-19 - dos itens incluídos nesta subcategoria destacam-se, por exemplo, o Município de Boticas (2020) quando se refere à utilização de infraestruturas onde habitualmente decorrem atividades culturais para acolher vitimas da pandemia, e o Município de Esposende (2020), o Município de Paredes 
(2020) e o Município de Vila Nova de Cerveira (2020) que destacam a canalização de verbas de eventos culturais cancelados para o combate à pandemia;

- não sendo a subcategoria com menos associações efetuadas, considera-se que os $4,0 \%$ de referências explícitas, em $28,6 \%$ dos municípios, as linhas de apoio específicas para o setor cultural podem ser reflexo dos poucos investimentos a que a cultura está, habitualmente, remetida - sublinha-se que em algumas das notícias enquadradas na subcategoria 11) se referem verdadeiramente a iniciativas municipais como a do Município de Braga (2020), que visou apoiar "a criação artística em tempos de pandemia", a do Município de Caldas da Rainha (2020), que incluiu um "programa de aquisições para ceramistas locais" e a do Município de Sintra (2020) com a criação de um "Fundo Municipal de Emergência Cultural", mas a verdade é que em alguns casos as notícias destinam-se, essencialmente, à divulgação de iniciativas da administração central do Estado, como a notícia publicada pelo Município de Águeda (2020) sobre o programa de apoio às artes;

- na subcategoria 12) foram enquadradas notícias que, não obstante responderem positivamente às palavras-chave definidas para a pesquisa, a análise das temáticas não se revelava substancialmente significativa para a autonomização de outras subcategorias, por tratarem temáticas mais genéricas em que as questões culturais estão incluídas e associadas a outras dimensões, como a ação social ou 0 apoio a empresas.

Para além dessa análise individual de cada um dos 3.955 títulos das notícias identificadas, nesteolhar qualitativo da amostra também incluímos a análise em blocoa partir das palavras mais usadas em todos os títulos:

- primeiro procedeu-se à eliminação de artigos, preposições e verbos auxiliares eà fusão de palavras em função do radical e do contexto;

- depois de efetuado o tratamento aos títulos, as palavras foram contabilizadas com recurso ao NVivo e foram elaboradas listas com as 30 palavras mais usadas - em função das dimensões temporal e territorial, integrando ou não as palavras-chave da pesquisa;

- por último foram criadas nuvens de palavras com as 30 palavras mais repetidas, com quatro ou mais letras, em que as buscas foram codificadas para agrupar palavras similares. 
A elaboração das listas com as 30 palavras mais usadas nos títulos nas diferentes desagregações elencadas permitiu-nos uma aproximação especial às grandes temáticas abordadas nas 3.955 notícias ao longo do semestre.

A título meramente ilustrativo do trabalho desenvolvido, apresentamos a Tabela 2, que integra na primeira coluna os dados globais e nas duas restantes colunas os dados desagregados em duas dimensões territoriais, à escala das NUT 2, escolhidas por serem, respetivamente, as que têm maior e menor volume de notícias identificadas. A análise da tabela permite-nos identificar algumas diferenças importantes no que concerne aos dois territórios em confronto e que podem ser úteis para, em momentos futuros, efetuar a triangulação com dados provenientes das outras dimensões do projeto de pesquisa:

- não obstante a RA Madeira ter sido a NUT com menos itens identificados ao longo do semestre e uma das que apresenta uma média de notícias por município mais baixa $(7,1 \%)$, a verdade é que se observa uma forte presença de notícias em que apalavra cultura e derivadas figuram de forma explicita - representando $1,34 \%$ das palavras mais usadas nos títulos, quando no Norte o valor homólogo baixa para os $0,9 \%$ e a nível nacional para os $0,67 \%$ - o que pode ser um sinal de que na RA Madeira se optou por encarar e resolver os constrangimentos provocados na cultura pelo COVID19 de forma autónoma e não de forma transversal ou diluída noutras dimensões da ação governativa;

- não deixa de ser interessante sublinhar que, provavelmente pelas caraterísticas dos serviços culturais que prestam, pelo peso que podem assumir nas dinâmicas culturais à escala local e por estarem disseminados em todo o país, que os equipamentos culturais mais referenciados nas notícias, independentemente da escala de análise, sejam as bibliotecas;

- sobre a presença de palavras comomedida(s)e apoio(s), salienta-se que, não raras vezes, são usadas para aspetos transversais da COVID-19 e não para a dimensão cultural em particular.

Tabela 2 - Palavras mais frequentes utilizadas nos títulos das notícias identificadas

\begin{tabular}{|c|c|c|c|c|c|c|c|c|}
\hline \multicolumn{3}{|c|}{ Total da amostra } & \multicolumn{3}{|c|}{ Norte } & \multicolumn{3}{|c|}{ RA Madeira } \\
\hline \multirow{2}{*}{ Palavra } & \multicolumn{2}{|c|}{ Ocorrência } & \multirow{2}{*}{ Palavra } & \multicolumn{2}{|c|}{ Ocorrência } & \multirow{2}{*}{ Palavra } & \multicolumn{2}{|c|}{ Ocorrência } \\
\hline & $N$ & $p$ & & $N$ & $p$ & & $n$ & $p$ \\
\hline Covid & 652 & 1,86 & Covid & 147 & 1,34 & Covid & 24 & 3,24 \\
\hline Municipal & 518 & 1,48 & Municipal & 141 & 1,29 & Funchal & 17 & 2,29 \\
\hline Município & 371 & 1,06 & Município & 90 & 0,82 & Municipal & 15 & 2,02 \\
\hline Medidas & 351 & 1,00 & Câmara & 88 & 0,80 & Plano & 12 & 1,62 \\
\hline Câmara & 283 & 0,81 & Medidas & 71 & 0,65 & Contingência & 10 & 1,35 \\
\hline
\end{tabular}




\begin{tabular}{|c|c|c|c|c|c|c|c|c|}
\hline Biblioteca & 251 & 0,72 & Casa & 66 & 0,60 & 2020 & 9 & 1,21 \\
\hline Plano & 231 & 0,66 & Plano & 65 & 0,59 & Medidas & 9 & 1,21 \\
\hline Abril & 229 & 0,65 & Biblioteca & 63 & 0,58 & Cultura & 7 & 0,94 \\
\hline 2020 & 212 & 0,60 & Contingência & 59 & 0,54 & Biblioteca & 6 & 0,81 \\
\hline Apoio & 208 & 0,59 & Feira & 59 & 0,54 & Câmara & 6 & 0,81 \\
\hline Contingência & 207 & 0,59 & Abril & 57 & 0,52 & Edital & 6 & 0,81 \\
\hline Casa & 191 & 0,54 & 2020 & 56 & 0,51 & Feira & 5 & 0,67 \\
\hline Comunicado & 162 & 0,46 & Comunicado & 49 & 0,45 & Casa & 4 & 0,54 \\
\hline Online & 160 & 0,46 & Apoio & 47 & 0,43 & Livros & 4 & 0,54 \\
\hline Municipais & 141 & 0,40 & Exposição & 46 & 0,42 & População & 4 & 0,54 \\
\hline Feira & 132 & 0,38 & Teatro & 40 & 0,37 & Sobre & 4 & 0,54 \\
\hline Concelho & 130 & 0,37 & Municipais & 39 & 0,36 & Abril & 3 & 0,40 \\
\hline Cultura & 125 & 0,36 & Museu & 38 & 0,35 & Amanhã & 3 & 0,40 \\
\hline Museu & 121 & 0,34 & Livro & 37 & 0,34 & Apresenta & 3 & 0,40 \\
\hline Coronavírus & 119 & 0,34 & Cultural & 36 & 0,33 & Comunicado & 3 & 0,40 \\
\hline Exposição & 116 & 0,33 & Eventos & 36 & 0,33 & Concelho & 3 & 0,40 \\
\hline Cultural & 108 & 0,31 & Cancelado & 35 & 0,32 & Concerto & 3 & 0,40 \\
\hline Empresas & 106 & 0,30 & Equipamentos & 35 & 0,32 & Cultural & 3 & 0,40 \\
\hline Eventos & 102 & 0,29 & Online & 33 & 0,30 & Curso & 3 & 0,40 \\
\hline Programa & 102 & 0,29 & Culturais & 32 & 0,29 & Direto & 3 & 0,40 \\
\hline Público & 101 & 0,29 & Internacional & 32 & 0,29 & Encerramento & 3 & 0,40 \\
\hline Internacional & 100 & 0,29 & Cultura & 31 & 0,28 & Esta & 3 & 0,40 \\
\hline Reabre & 93 & 0,27 & Reabre & 31 & 0,28 & Festas & 3 & 0,40 \\
\hline Equipamentos & 92 & 0,26 & Agosto & 30 & 0,27 & Funchalenses & 3 & 0,40 \\
\hline Reabertura & 91 & 0,26 & Coronavírus & 28 & 0,26 & Online & 3 & 0,40 \\
\hline
\end{tabular}

Fonte: Elaboração própria

Para a criação das nuvens de palavras mais utilizadas nos títulos das notícias, optou-se por fazer, para cada uma das listagens, duas versões: a primeira incluindo as três palavras-chave do projeto, que evidentemente estão muito presentes nos títulos; e a segunda excluindo nas listagens as três palavras-chave, permitindo, desta forma, ter uma melhor perceção visual do peso relativo das restantes palavras de cada listagem.

A título meramente ilustrativo, apresentamos a Figura 1 e a Figura 2 com as 30 palavras mais usadas nos títulos das notícias agrupadas à escala das NUTS 2.

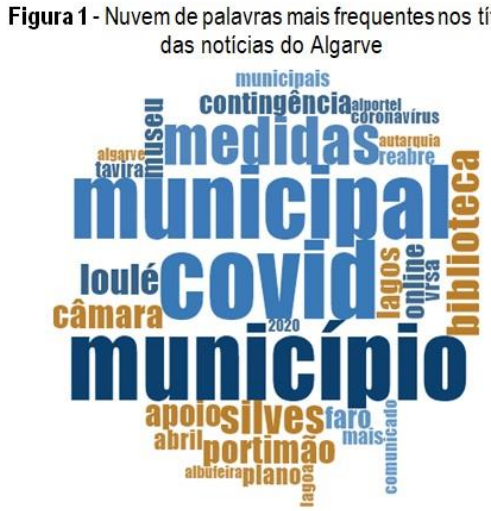

Fonte: Elaboração própria
Figura 2 - Nuvem de palavras mais frequentes nos títulos das noticias de Lisboa e Vale do Tejo

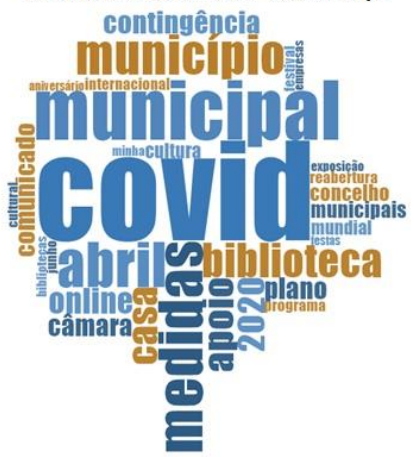

Fonte: Elaboração própria 
Da Figura 1, referente às 221 notícias identificadas nos 16 websites dos municípios do Algarve, salientamos a referência explícita a vários dos municípios que compõem essa NUT 2 Albufeira, Faro, Lagos, Loulé, Portimão, Tavira, São Brás de Alportel, Silves, Vila Real de Santo António - o que é particularmente relevante no que diz respeito à descentralização cultural, tanto mais que, não raras vezes, as notícias relacionadas com a cultura estão centralizadas num grupo reduzido de municípios. De entre as nuvens de palavras geradas, decidimos incluir a Figura 2, referente a Lisboa e Vale do Tejo, por ser a única NUT que viu incluída a palavra internacional no conjunto das 30 mais utilizadas, para sublinhar o pouco investimento na dimensão internacional das políticas culturais portuguesas à escala local, apesar de, fruto da pandemia, se ter cancelado ou adiado a generalidade dos festivais internacionais agendados para Portugal no ano de 2020.

\section{NOTA DE ENCERRAMENTO}

Como referido na Nota de Abertura, mais do que apresentar conclusões fechadas, este artigo integra-se na estratégia de disseminação dos resultados do projeto, no âmbito da qual estamos a disponibilizar regularmente a análise, ainda que preliminar, dos dados que vão sendo recolhidos, pois só assim poderão ser relevantes na procura de soluções para os impactos que a COVID-19 terá no tecido cultural português.

No presente artigo convocamos, sinteticamente, parte da análise consolidada de dados recolhidos na segunda dimensão do estudo ao longo do primeiro semestre da pandemia.A análise dos 308 websites de municípios permitiu identificar 3.955 notícias sobre COVID-19 e cultura - na realidade o fluxo de notícias identificado foi inferior, uma vez que no levantamento de itens se entrou em linha de conta, independentemente de abordar explicitamente questões relacionadas com a cultura, a primeira notícia sobre a COVID-19 publicada no mês de março nos websites. A distribuição das notícias pelo território não foi equitativa, sendo que os resultados obtidos revelam o pouco peso estratégico que a cultura tem em muitas das dinâmicas das políticas municipais, não podendo, contudo, ser estabelecida neste momento uma relação direta entre o fluxo noticioso e a escala ou a localização dos municípios. Observamos, regra geral, um privilégio de temáticas relacionadas com os impactos negativos (e.g. adiamento/cancelamento de eventos, suspensão de atividades, encerramento de instalações), em detrimento de notícias com medidas das autarquias locais para a mitigação, a curto e médio prazo, dos impactos negativos nas organizações e profissionais do setor cultural. Destaca-se ainda como preocupantea presença residual de notícias sobre a temática COVID-19 e cultura na generalidade dos websites das 25 EIM's.A este respeito convém não esquecer que também cabe às EIM's assegurar a articulação das atuações entre os municípios e os serviços da administração central na área das redes 
de equipamentos culturais, e também compete aos conselhos das entidades intermunicipais aprovar os planos, os programas e os projetos de investimento e desenvolvimento de interesse intermunicipal na área da cultura.

Desse modo, apesar de ser um projeto em curso, pensamos que esta análise preliminar já nos apresenta dados importantes sobre o papel das políticas públicas à escala municipal para mitigar os impactos negativos da pandemia no setor cultural português, que se triangulados com os dados provenientes das restantes dimensões do estudo, permitirão analisar em profundidade os Impactos da COVID-19 no setor cultural português.

Assim sendo, e mesmo a terminar, vamos convocar três tópicos sobre os resultados preliminares das restantes dimensões do projeto e que podem ajudar a identificar algumas das tendências que se estão a observar:

1) a análise efetuada aos impactos mediáticos da COVID-19, através de sete jornais portugueses e da Agência Lusa permite-nos afirmar, ainda que provisoriamente, que a maioria das notícias abordam os impactos negativos da COVID-19 no setor cultural português e que, apesar de $1 / 4$ das notícias incidir sobre as iniciativas públicas, a verdade é que, não raras vezes, há um enfoque que não é particularmente positivo sobre o papel do Governo para mitigar os efeitos da pandemia - acresce ainda que, não obstante a considerável cobertura mediática das consequências da COVID-19 no setor cultural português, a cultura continua a não constituir uma prioridade editorial da imprensa portuguesa;

2) a atividade parlamentar e as iniciativas do Governo para fazer face aos constrangimentos provocados pela COVID-19, foram também reveladores do protagonismo da cultura na escala de prioridades dos atores políticos, tendo o setor cultural sido remetido, não raras vezes, para as medidas transversais adotadas pelo Governo;

3) as organizações e os profissionais do setor cultural, auscultados através de um inquérito por questionário, não deixaram margem para dúvidas, revelando que, se não forem tomadas medidas urgentes, substantivas e estruturantes, o setor cultural português poderá sofrer danos irreparáveis como fruto da pandemia.

\section{REFERÊNCIAS}

BARDIN, Laurence. Análise de Conteúdo. Lisboa: Edições 70, 2007. 
BELL, Judith. Como realizar um projecto de investigação. Lisboa: Gradiva, 2008.

CASQUEIRA, Natália Azevedo. Políticas Culturais, Turismo e Desenvolvimento Local na Área Metropolitana do Porto. Tese de doutoramento, Faculdade de Letras, Universidade do Porto, Portugal, 2007. Disponível em: http://ler.letras.up.pt/site/default.aspx?qry=id06id1203\&sum=sim. Acesso em: 30 nov. 2020.

CHAUMIER, Jacques. LesThechniquesDocumentaires. Paris: Presses Universiatires de France. 1979.

CINAMATECA PORTUGUESA. Plano de Contingência COVID - 19 Cinemateca Portuguesa Museu do Cinema, IP.Disponível em: http://www.cinemateca.pt/CinematecaSite/media/Banners/Planode-Contingencia-Cinemateca.pdf. Acesso em: 20 abr. 2020.

CRESWELL, John. Planning, Conducting, and evaluating quatitative and qualitative research. 3 ed. Merril Prentice Hall. 2008.

FERNANDES, António José. Introdução à Ciência Política - Teorias, Métodos e Temáticas. Porto: Porto Editora. 2010.

INSTITUTO NACIONAL DE ESTATÍSTICA I.P. Conta Satélite da Cultura - 2010-2012. Notas metodológicas. 2016. Disponível em:

https://www.ine.pt/xportal/xmain?xpid=INE\&xpgid=ine_docmetodsec2010_cn\&perfilpagenumber=2\&perf il=220674570\&contexto=c. Acesso em: 16 mar. 2020.

MATOS, Madalena. Metodologias qualitativas e quantitativas: de que falamos?, Forum Sociológico [Online], 24 | 2014, posto online no dia 01 novembro 2014. Disponível em: http://journals.openedition.org/sociologico/1061. Acesso em: 15 de maio de 2020.

MEDICINES AND HEALTHCARE PRODUCTS REGULATORY AGENCY. UK medicines regulator gives approval for first UK COVID-19 vaccine. MHRA, 2 dez. 2020. Disponível em:https://www.gov.uk/government/news/uk-medicines-regulator-gives-approval-for-first-uk-covid-19vaccine. Acesso em: 15 dez. 2020.

MUNICÍPIO DE ÁGUEDA. Linha apoia setor das Artes. 31 mar. 2020. Disponível em: https://www.cm-agueda.pt/pages/48?news_id=1913. Acesso em: 1 abr. 2020.

MUNICÍPIO DEBOTICAS. Pavilhão Multiusos preparado com 45 camas. 27 mar. 2020. Disponível em:http://www.cm-boticas.pt/noticias/default.php?id=CK. Acesso em: 1 abr. 2020.

MUNICÍPIO DE BRAGA. Braga apoia a criação artística em tempos de pandemia.18mai. 2020. Disponivel em:https://www.cm-braga.pt/pt/0201/comunicacao/noticias/item/item-1-10901. Acesso em: 1 jun. 2020.

MUNICÍPIO DE CALDAS DA RAINHA. COVID19: Câmara lança programa de aquisições para ceramistas locais. 20 jul. 2020. Disponivel em: http://www.cm-caldasrainha.pt/webcenter/portal/mcr/Noticias?id=36262\&_adf.ctrl-

state=tr8gxdeuu_1\&_afrLoop=2095396634092032\#!\%40\%40\%3F_afrLoop\%3D2095396634092032\%2 6id\%3D36262\%26_adf.ctrl-state\%3Dtr8gxdeuu_5. Acesso em: 1 ago. 2020. 
MUNICÍPIO DE CASCAIS. COVID-19. Já pode ver peças de teatro em casa. 6 abr. 2020. Disponível em:https://www.cascais.pt/noticia/covid-19-ja-pode-ver-pecas-de-teatro-em-casa. Acesso em: 16 abr. 2020.

MUNICÍPIO DE ESPOSENDE. Município de Esposende canaliza verbas dos eventos para combate à pandemia COVID-19. 24 mar. 2020. Disponível

em:https://www.municipio.esposende.pt/pages/703?news_id=5213. Acesso em: 1 abr. 2020.

MUNICÍPIO DE MATOSINHOS. As Festas do Senhor de Matosinhos foram canceladas. 7 abr. 2020. Disponível em: https://www.cm-matosinhos.pt/pages/242?news_id=6852. Acesso em: 16 abr. 2020.

MUNICÍPIO DE PALMELA. "De minha casa vejo o mundo": partilha a vista da tua janela! 31 mar. 2020. Disponível em: https://www.cm-palmela.pt/pages/1717?news_id=6718. Acesso em: 1 abr. 2020.

MUNICÍPIO DE PAREDES. Câmara de Paredes vai reforçar os apoios sociais aos paredenses com mais necessidades aplicando as verbas dos eventos culturais e desportivos.18 mar. 2020. Disponível em:https://www.cm-paredes.pt/pages/1059?news_id=1170. Acesso em: 1 abr. 2020.

MUNICÍPIO DE SINTRA. Abertas as candidaturas ao Fundo Municipal de Emergência Cultural.3 jun. 2020. Disponível em:https://cm-sintra.pt/atualidade/noticias-institucional/abertas-as-candidaturasao-fundo-municipal-de-emergencia-cultural. Acesso em: 16 jun. 2020.

MUNICÍPIO DE VILA NOVA DE CERVEIRA. Verba de eventos culturais suspensos/cancelados reforçam IPSS's com material de higienização.18 mar. 2020. Disponível em:https://www.cmvncerveira.pt/pages/348?news_id=1959. Acesso em: 1 abr. 2020.

MUNICÍPIO DO PORTO. Fórum do Futuro não se realizará em 2020 mas vai ter uma edição em livro. 28 jul. 2020. Disponível em:https://www.porto.pt/pt/noticia/forum-do-futuro-nao-se-realizara-em2020-mas-vai-ter-uma-edicao-em-livro. Acesso em: 1 ago. 2020.

ORGANIZAÇÃO MUNDIAL DE SAÚDE (a). WHO Director-General's opening remarks at the media briefing on COVID-19 - 11 March 2020. WHO, 11 mar. 2020. Disponível em: https://www.who.int/dg/speeches/detail/who-director-general-s-opening-remarks-at-the-media-briefingon-covid-19---11-march-2020. Acesso em: 18 mar. 2020.

ORGANIZAÇÃO MUNDIAL DE SAÚDE (b). Novel Coronavirus - China. WHO, 12jan. 2020. Disponível em: https://www.who.int/csr/don/12-january-2020-novel-coronavirus-china/en/. Acesso em: 18 mar. 2020.

PINTO, José Volta. Em dias de coronavírus, o teatro chega às plateias através da Internet. Público, P3, 12 mar. 2020. Disponível em: https://www.publico.pt/2020/03/12/p3/noticia/dias-coronavirus-teatrochega-plateias-atraves-internet-1907471.Acesso em: 1 abr. 2020.

PORTUGAL Lei n. ${ }^{0}$ 75/2013 de 12 de setembro. Estabelece 0 regime jurídico das autarquias locais, aprova 0 estatuto das entidades intermunicipais, estabelece o regime jurídico da transferência de competências do Estado para as autarquias locais e para as entidades intermunicipais e aprova 0 regime jurídico do associativismo autárquico. Diário da República n. ${ }^{0}$ 176/2013, Série I de 2013-09-12, p. 5688-5724. 
PORTUGAL Decreto n. ${ }^{\circ}$ 2-A/2020 de 20 de março. Procede à execução da declaração do estado de emergência efetuada pelo Decreto do Presidente da República n. ${ }^{\circ}$ 14-A/2020, de 18 de março. Diário da República n. ${ }^{0} 57 / 2020,1^{\circ}$ Suplemento, Série I de 2020-03-20, p. 11-(5) a 11-(17).

PORTUGAL Decreto-Lei n. ${ }^{0}$ 10-A/2020 de 13 de março. Estabelece medidas excecionais e temporárias relativas à situação epidemiológica do novo Coronavírus - COVID 19.Diário da Repúblican. ${ }^{0}$ 52/2020, $1^{\circ}$ Suplemento, Série I de 2020-03-13, p. 22-(2) a 22-(13).

QUIVY, Raynond; CAMPENHOUDT, Luc Van. Manual de Investigação em Ciências Sociais. Lisboa: Gardiva. 2005.

SAMPIERI, Roberto Hernández; COLLADO, Carlos Hernández; LUCIO, Pilar Baptista. Metodologia de Investigação. São Paulo: McGraw-Hill. 2006

SANTOS, Maria de Lourdes Lima. (coord.). As Políticas Culturais em Portugal. Lisboa: Observatório das Actividades Culturais. 1998.

\section{Notas}

1Ver mais informações em: http://polobs.pt/estudo/impactoss-da-covid-19-no-setor-cultural-portugues/ 